\title{
COMPREENSÕES SOBRE A PRETENSA EDUCAÇÃO \\ AMBIENTAL DO ESTADO SOB A CRÍTICA DA ECOLOGIA POLÍTICA: AS RELAÇÕES ENTRE A EMATER E UMA COMUNIDADE DE PESCA ARTESANAL NA DÉCADA DE 1990
}

Lisiane Costa Claro ${ }^{1}$

Vilmar Alves Pereira ${ }^{2}$

Resumo: A pesquisa ocorre a partir do estudo de dois projetos responsáveis por algumas práticas incentivadas pelo Estado em um espaço pesqueiro artesanal, junto a Laguna dos Patos no estado do Rio Grande do Sul, Brasil, na década de 90. A llha da Torotama (Rio Grande/RS) carrega algumas imagens construídas a partir das intervenções que a EMATER realizou, no período em evidência, ao propor alguns projetos de cunho educativo nesse contexto. Ao utilizar a Análise Documental (LeGoff, 1995), com o auxílio da Ecologia Política, compreende-se que as noções de Educação Ambiental tomadas pelo Estado pautam-se numa racionalidade tecnocêntrica, cientificista, que negligencia os saberes tradicionais das camadas populares.

Palavras-chave: Educação Ambiental; Estado; Ecologia Política; EMATER; Pesca Artesanal.

1Universidade Federal do Rio Grande - FURG. E-mail: lisianecostaclaro@gmail.com

2 Universidade Federal do Rio Grande - FURG E-mail: vilmar1972@gmail.com 


\section{Introdução}

O estudo trata das ações de cunho educativo ambiental realizadas pela EMATER na llha da Torotama durante a década de 1990. O interesse sobre essa discussão parte da necessidade de problematizar o que está banalizado socialmente. Uma das falácias de cunho fatalista voltadas à comunidade ocorre a partir do discurso proferido repetidamente sobre a ideia de que a pesca está em crise e que o futuro, dos que hoje são pescadores artesanais, não conceberá a pesca enquanto uma realidade. E nesse ponto, é inegável que há uma crise instaurada no que se refere à atividade pesqueira artesanal. Basta atentar para pesquisas de autores como Diegues (1995), Lam (1998) e Cardoso (2001) que bem demonstram o quanto a pesca artesanal é uma atividade que enfrenta uma série de dificuldades, tanto pelos entraves das políticas ambientais, que em muitos casos estão descoladas da realidade dos pescadores artesanais, quanto pelas questões climáticas - que em grande parte têm a ação humana enquanto agravante, resultado de uma lógica do lucro desenfreado.

No entanto, a ecologia política vem demonstrando que as práticas tecnocráticas não contemplaram as soluções necessárias aos desequilíbrios ambientais, tampouco resolveram os conflitos no bojo conceitual racionalista (ACSELRAD, 2006). A questão é que se na década de 1990, assistimos nas comunidades tradicionais algumas ações locais que não atingiram o cerne dos conflitos ambientais, mais recentemente não temos um cenário que apresente grandes avanços, a não ser o agravamento dos conflitos incitados pelo mercado nas décadas de 1960 e $1970 \mathrm{com}$ o aumento do parque industrial pesqueiro. Para tanto estaremos alicerçados em autores que abordem a possibilidade de problematizar os fenômenos socioambientais a partir da ecologia política, como Leff (2003).

Nesse horizonte, buscamos problematizar as ações de cunho educativo presentes no espaço em questão. Propõem-se, sobretudo, investigar a concepção que o Estado apresentava no período em foco sobre o que chamava de Educação Ambiental e como essa noção atua na formulação de imagens lançadas em torno dessa llha. Ao compreender que a década de 1990 foi um período que apostou em uma política de cunho neoliberal e desenvolvimentista, questionamos: Quais ações eram realizadas junto a comunidade de pesca na Torotama na década de 1990? O que essas práticas demonstravam acerca da concepção de Educação Ambiental concebida no âmbito do Estado?

O enfrentamento dessa problemática, parte da Análise Documental (LE GOFF, 1995) utilizada para a análise de dois relatórios produzidos a partir de ações realizadas pela EMATER na referida llha. Duas ações são postas em estudo: uma delas nomeada, em um dos relatórios como, "O Projeto Educação Ambiental junto ao Programa de Formação Social", a segunda trata-se do "Programa de Promoção Social". 


\section{A llha da Torotama}

A chamada "Ilha da Torotama" está localizada no município de Rio Grande, no estado do Rio Grande do Sul. A cidade possui 197.228 habitantes e tem grande movimentação na área portuária, bem como abarca várias indústrias de fertilizantes e possui um polo naval. Cabe salientar que se considera o território enquanto um espaço construído historicamente e por meio da sociedade no qual a eficiência das atividades econômicas é fortemente condicionada pelos laços de proximidade e pelo sentido de pertencimento a esse ambiente (NIEDERLE; GRISA, 2006). Esse panorama atual do município representa uma forte mudança no que tange ao desenvolvimento da pesca no território em questão. Desse modo, a partir das informações obtidas por meio do censo realizado pela FAO em 2009/2010, existem 1.148 pescadores artesanais no município de Rio Grande (KALIKOSKI; VASCONCELLOS, 2012).

Segundo Opuszka (2010) organizações como associações de pesca artesanal e colônia de pescadores tiveram início a partir de lutas políticas dos pescadores da Laguna dos Patos e, logo, outros grupos foram se incorporando a uma situação de disputa pelo trabalho característico dessa região, na medida em que sofriam as consequências da atividade econômica realizada em Rio Grande. Esse evento foi suscitado por meio da pesca industrial instalada em Rio Grande e posteriormente, pela indústria portuária.

A partir desse processo descrito, é interessante ressaltar a observação que Certeau (1995) realiza ao salientar a ideia de que os grupos minoritários enfrentam a problemática inicial na busca por autonomia cultural, social ou étnica ao manifestar-se dizendo "não". Com efeito, aqui se traz a necessidade percebida por parte dos pescadores artesanais em negar sua atividade no que tange à pesca industrial. "Não somos pescadores industriais, somos pescadores artesanais", dizem os pescadores da Torotama ao unir-se em grupos a partir de uma intenção comum: o reconhecimento e a busca por melhores condições de seu ofício.

Sobre o lugar que abarca a Ilha, Martins (2002) afirma que o município de Rio Grande se situa na desembocadura da Laguna dos Patos, interagindo com os ecossistemas oceânico atlântico, lacustre e estuariano-lagunar. O autor defende que esse domínio natural é objeto de estudos pertinentes de suas condições. Assim, a respeito da região do Estuário sabe-se que a mesma é banhada por água doce, com entrada sazonal, de água salgada (Figura 1) - o que varia de acordo com a época no ano -. Dessa maneira, se torna possível o desenvolvimento de espécies como o camarão e outros peixes (em diferentes períodos do ano). 


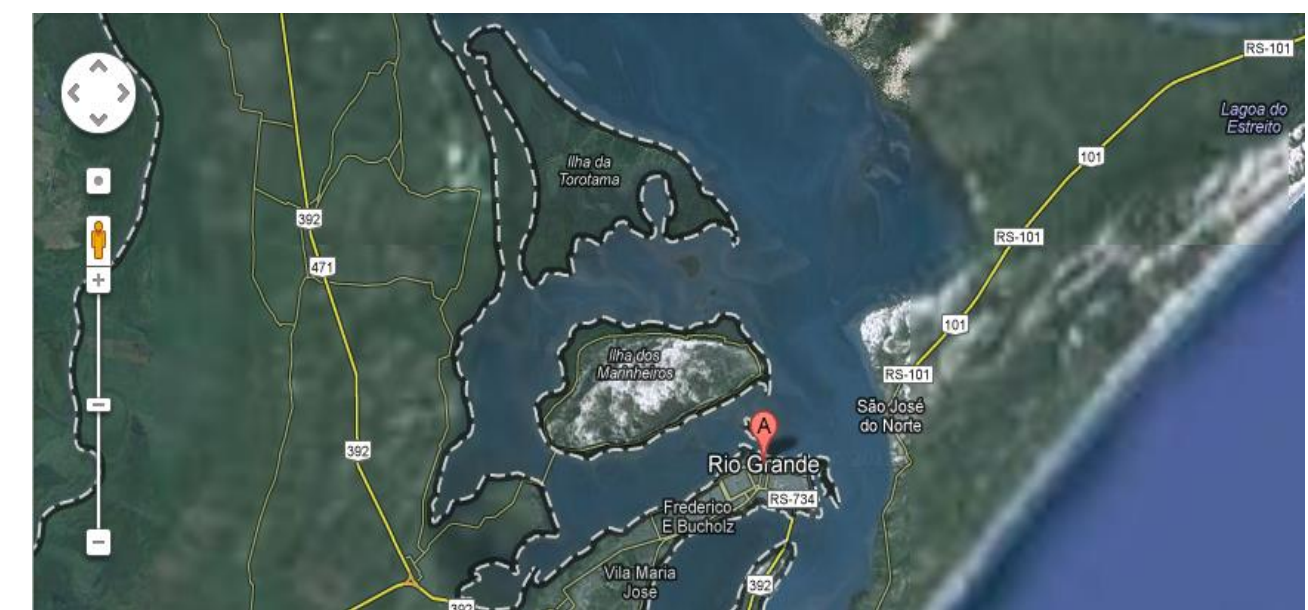

Figura 1: Mapa de localização da llha da Torotama no município de Rio Grande (RS).

Fonte: Google Maps. Acesso em 27.06.2012 às 13h47min

Conforme Diegues (1997) - o qual toma enquanto aporte Moles (1982), Perón (1993) e Coddacioni-Meisterheim (1989) - ao abordar o espaço de llha, existem dois conceitos os quais auxiliam na compreensão acerca desse ambiente: insularidade e ilheidade. A insularidade é compreendida enquanto "fenômenos sociais resultantes do relativo isolamento dos espaços insulares e que podem ser quantificados (a distância do continente, etc.)" (DIEGUES, 1997, p.12). O autor apresenta que é preciso distinguir a insularidade do isolamento; "as ilhas, ainda que parcialmente isoladas, não se desenvolvem sistemas fechados; vivem ao contrário em ritmos alternados de abertura e fechamento, segundo as formas pelas quais estão ligadas à sociedade continental ampla" (DIEGUES, 1997, p.12). Assim, apesar de o espaço manter suas peculiaridades, o mesmo está vinculado ao continente. Acredita-se que esse fenômeno deva ser considerado ao investigar o que os ilhéus pensam sobre o ambiente que constituem. Já a respeito da ilheidade, a mesma constitui-se das imagens decorrentes da insularidade expressadas por mitos fundadores da ilha e de sua comunidade de forma em que "diz respeito também ao vivido pelos ilhéus, aos comportamentos induzidos pela natureza particular do espaço insular" (DIEGUES, 1997, p.12).

Ao buscar entender parte da insularidade e ilheidade desse ambiente, destacam-se algumas manifestações específicas da comunidade: o lazer e o trabalho da pesca. O lazer na comunidade ocorre junto ao sentimento de pertencimento e rivalidade. Referimo-nos aos dois times de futebol amador presentes na llha: Fiateci e Novo Avante.

Os times além de incentivarem atividades de lazer, aperfeiçoamento, por meio de convênios e parcerias com outras instituições, fomentam o carnaval na comunidade. Os times realizam um processo de organização do desfile, incluindo fantasias, enredo e ornamentação das sedes. Após a preparação para a saída pela comunidade, os times se cruzam no caminho e seguem até o clube rival para verificar a mobilização e arranjos para o evento. Essa tradição representa uma manifestação ritualizada a qual está muito presente no espaço. Além disso, é comum os moradores dessa localidade Revbea, São Paulo, V. 11, № 5: 89-100, 2017. 
referenciarem com orgulho os nomes dos fundadores dos times, bem como exjogadores, presidentes de clube, enfim, personagens que fizeram parte dessa história local. É visível a admiração para com esses sujeitos, ainda mais quando a maioria da população é descendente desses atores sociais.

Nesse permeio, sobre o trabalho da pesca percebe-se a importância para com o ofício que foi perpassando a cada geração. Os pescadores sentem orgulho de sua função, não obstante preocupam-se com o futuro incerto da pesca devido à escassez do pescado cada vez mais intensa na região. Muitos pescadores iniciaram a atividade da pesca desde o inicio da adolescência com seus pais. As mulheres, na maioria dos casos, apesar de não irem à laguna, realizam o processo da limpeza e qualificação do pescado e do camarão, de acordo com a época do ano. Muitas se assumem enquanto pescadoras, se compreendem como tal e reclamam quando as apontam como "a mulher do pescador", exclamando que essa frase está incompleta e ajustando: "a mulher do pescador, a pescadora". Algumas realizam o processo de pesca na laguna, postos muitas vezes ocupados quando da ausência dos homens na família, ou mesmo, por gosto e costume desde o final da infância.

\section{Práticas Educativas e Concepções acerca da Educação Ambiental do Estado sob o enfoque de uma Ecologia Política}

Cabe destacar que durante o período dos documentos estudados, temos um cenário bem definido na América Latina, e, também podemos apropriá-lo, em determinados pontos, ao contexto brasileiro que é o espaço aos discursos e propostas neoliberais e fortificação das imposições do mercado global. Assim:

Lembramos que na década de noventa o Consenso de Washington colocou no centro da agenda a valorização financeira e levou uma ma política de ajustes e privatizações, que acabam por redefinir o estado como um agente metaregulador. Ele também operou uma espécie de homogeneização política na região, marcada pela forte identificação ou proximidade com as receitas do neoliberalismo (SVAMPA, 2013, p.19).

Dessa forma, a EMATER ajusta-se a uma política de cunho privado, porém representando o Estado. Identificamos o que Svampa (2013, p.236) chama de "boa governança":

como entendido pelos governos, como o brasileiro, aplicaram a prescrição liberal abdicando de sua responsabilidade em relação às políticas sociais, como educação e meio ambiente e aquela que, consequentemente, instituiu a figura do "bom pobre", invisível e que se assume a si mesmo e a seu povo sem pedir nada a coletividade, que subordina a saúde da população à saúde dos bancos e a sustentabilidade ambiental à sustentabilidade dos fluxos financeiros especulativos. 
Com efeito, o Estado ao articular-se com a esfera privada, descompromete-se com as responsabilidades frente às políticas sociais, como a educação e o meio ambiente ao atribuir os efeitos da lógica liberal ao setor privado. É nessa conjuntura que o relatório o qual aborda um projeto de Educação Ambiental realizado entre o ano de 1991 e 1993, na localidade da Torotama, aponta:

O Projeto Educação Ambiental é realizado na llha da Torotama, coordenado pelo IBAMA, SMAIC, e SMEC, tem o apoio e a participação da EMATER. Visa adequar a escola à realidade da comunidade, já que a mesma serve como fonte de informação, estimulando a organização e a participação da comunidade com vistas a defesa do meio ambiente e melhoria de qualidade de vida (Relatório EMATER - Rio Grande de 1991 a 1993, p. 9 , 1994).

Assim, considera-se a intervenção do poder público na comunidade por meio de parcerias e disposto a incentivar os cuidados que os moradores deveriam ter em relação ao seu ambiente. Ao apontar a necessidade de melhoria de qualidade de vida, compreende-se que o Estado reconhece a existência de algumas carências enfrentadas pela comunidade. A ação ocorre a partir de parcerias entre diferentes instâncias do poder público e junto à lógica da Empresa. Cabe ressaltar, o que, segundo Ascelrad (2006), Jacques Rancière chama de pós-democracia consensual, caracterizado pelo sumiço da política, encobrimento dos conflitos e designação de alguns segmentos da sociedade como capazes de negociar com o Estado em uma relação de "sócios". A lógica do mercado presente nos espaços de governo público, abre uma enorme vala entre as discussões sobre os conflitos sociais e as tomadas de decisão política, num processo de despolitização de alguns segmentos sociais e, paralelamente, estipulando alguns segmentos enquanto parceiros de decisões. Seriam esses, mecanismos necessários para o que o autor chama de política-espetáculo.

O que faz então, o poder público, nessa condição de "negociação em relação de sócios", para reverter uma situação que requer a "melhoria de qualidade de vida"? O relatório registra:

O trabalho teve início em maio de 1993, com reuniões de comunidade e levantamento de dados. Hoje, são realizados 2 cursos, um de corte de cabelo e Permanente para 09 pessoas e outro de fiação de lã crua para10 pessoas. o objetivo dos cursos é de mão-de-obra alternativa, já que a atividade principal dos moradores da llha é a pesca (Relatório EMATER Rio Grande de 1991 a 1993, p. 9, 1994). 西

\footnotetext{
Quando o documento descreve as atividades realizadas junto a comunidade, enquanto possibilidades de "mão-de-obra alternativa", compreende-se que há o entendimento por parte do Estado de que a pesca não representa uma atividade suficiente no que tange ao sustento dos Revbea, São Paulo, V. 11, № 5: 89-100, 2017.
} 
moradores locais. Portanto, ao invés de discutir os desafios existentes na pesca artesanal, o poder público busca incentivar a comunidade a encontrar outras formas de obtenção de renda para seu sustento. A Educação Ambiental serviria, então, como uma possibilidade de educar os sujeitos para outras formas de se viver, que não a partir dos saberes tradicionais da comunidade, dadas as problemáticas oriundas da atividade pesqueira.

Sabemos, segundo Souza (2001), que a crise da pesca no município de Rio Grande e região tem origem com os incentivos a pesca predatória voltada à industrialização do pescado, que ocorre a partir de 1960. Nesse ínterim, destacamos a validade ao analisar, de forma crítica, esse processo de abandono ao debate acerca dos conflitos a partir da ecologia política:

Levando em consideração os desequilíbrios provocados pela atividade humana, a ecologia política passa a se interrogar acerca da modernidade e a desenvolver uma análise crítica do funcionamento das sociedades industriais. Essa análise questiona um certo número de valores e de conceitos-chave sobre os quais se apoia nossa cultura ocidental (LIPIETZ, 2002, p.18).

Com efeito, a ecologia política abre um espaço que busca questionar uma série de concepções que foram forjadas no bojo de uma lógica na qual distancia o homem da natureza, colocando essa em uma posição de domínio para atender as necessidades criadas pelo sistema capitalista. Assim, com relação aos cuidados que deveriam ser tomados pela comunidade em relação ao seu ambiente, verificamos o registro:

Foi realizado na Escola Cristóvão Pereira de Abreu, para 40 crianças, um curso sobre o Estudo da Comunidade Estuarina, para que as mesmas conhecessem as espécies de peixes existentes na localidade e seu desenvolvimento natural, com o objetivo de preservar as espécies e garantir uma melhor produção futura (Relatório EMATER - Rio Grande de 1991 a 1993, p. 9, 1994).

Reconhecemos a iniciativa tomada com o propósito de incentivar os filhos dos pescadores, estudantes e moradores da localidade, a conhecerem mais sobre o lugar que habitam. Nesse processo de saber, seria reforçada a necessidade de preservação acerca do pescado. No entanto, sabe-se que a maior causa da escassez da pesca nesse período, ocorre a partir das consequências da atividade industrial exploratória da pesca na região, como já mencionado e que, sem a preocupação com a conservação natural do produto, gerou a partir de 1980 a diminuição do pescado (SOUZA, 2001).

Nesse sentido, após o incentivo Estatal para a obtenção de um grande volume do pescado, o qual ocorreu a partir do interesse do mercado exterior, o poder público parece, no contexto da década de 1990, lançar a 
responsabilidade da escassez das espécies para a comunidade pesqueira artesanal ao salientar a necessidade de preservação das espécies na llha da Torotama. Todavia, "uma sociedade sem projeto político, entregue às forças do mercado e sugada pela espiral do 'produzir cada vez mais' só pode levar ao crescimento das desigualdades sociais e das crises ecológicas" (LIPIETZ, 2002 , p. 20). Nesse horizonte, é apresentada a necessidade de uma nova postura e consciência que aborde os significados e as práticas atribuídos à dimensão política.

Contraditoriamente, por meio do relatório, há a construção da imagem do pescador artesanal como aquele que ignora o ciclo reprodutivo e de crescimento do pescado, como aquele responsável pela crise instaurada e que uma boa "produção futura" dependeria da ação de preservação da própria comunidade.

Com relação à outra forma de intervenção na comunidade desse período, pelo poder público junto a EMATER, analisamos os registros do "Programa de promoção social" o qual "visa o bem-estar e a saúde da família rural, através da adoção de práticas sobre alimentação, saúde, educação, habitação e lazer, porém devido ao baixo poder aquisitivo, hábitos de higiene e tabus, o êxito do trabalho fica dificultado" (Relatório EMATER - Rio Grande, 1994, p.10). Por meio desse registro, o relatório aponta que houve certa resistência por parte da comunidade em receber o programa planejado. Questão essa que é justificada, segundo o documento, pelo "baixo poder aquisitivo, hábitos de higiene e tabus" da comunidade. É preciso salientar que a chegada da água potável na llha da Torotama ocorreu em 20 de agosto de 1993, não com o abastecimento nas residências da localidade, mas, "puxando" a água do Banhado Silveira até uma única caixa d'água comunitária . Aqui se percebe uma possível construção da imagem de "atraso", a qual culpabiliza o próprio povo por não ter um maior "poder aquisitivo", ou usufruir dos recursos de uma infraestrutura básica.

Ainda sobre o programa enfatizado pela EMATER:

A área de bem-estar assiste, atualmente, a 06 grupos de senhoras e moças e uma associação comunitária, num total de 97 famílias. Atende, também, 15 escolas, 741 alunos, e 30 professores da rede municipal rural, através dos programas de alimentação (horta e merenda escolar) e saúde (saúde oral e cólera).

O programa de saúde oral consiste no uso do flúor no combate à cárie dentária, com o objetivo de minimizar o índice de cárie em crianças com idade entre 06 e 12 anos. Esse trabalho é integrado com o SESI, SMEC e escolas rurais e vem sendo realizado desde 1991, onde a extensionista orienta os professores que repassam as informações aos alunos. Pais e professores têm constatado que diminuiu em $60 \%$ o índice da cárie dentária junto aos alunos que participam do programa (Relatório EMATER - Rio Grande correspondente ao ano de 1994, p. 10).

Revbea, São Paulo, V. 11, № 5: 89-100, 2017. 
As práticas registradas acima abarcavam a llha da Torotama, a qual, assim como demais localidades do município consideradas rurais, e, participantes do programa, era compreendida enquanto um espaço carente de recursos - os quais eram compensados por intervenções assistencialistas. Portanto é nesse contexto, existentes nos anos 80 e intensificados na década seguinte, que os discursos neoliberais encontram espaços para disseminação, instigando a ideia de "qualificação" e "competência". No cenário brasileiro, durante esse período o mercado abre-se as demandas globais de forma a intensificar as desigualdades sociais sob o discurso da necessidade do desenvolvimento econômico, as políticas públicas estavam alicerçadas sobre questões técnicas e de soluções superficais, como podemos perceber nos relatórios.

Para além destas tendências que o período enfatizado seguia, ao corroborar políticas de cunho técnico, ao parecer negligenciar as linguagens e saberes locais, Pereira (2016) lembra que os tempos nos quais vivemos são declarados como sendo a Era Antropocena. Esta era que seria marcada em sua última instância pelo "movimento que desperta consciência de si mesmo que emerge mediante a chamada modernidade reflexiva e dos dilemas da sustentabilidade" (PEREIRA, 2016, p. 47). Em contraponto à este fenômeno, o autor sugere uma Ecologia Cosmocena:

Uma alternativa para pensarmos as relações entre os seres vivos e os não vivos no sentido de podermos garantir melhor qualidade de vida no planeta e, quem sabe, no universo. Ela nasce em meio a este cenário de desesperança e medo reforçado pela Era Antropocena e pelas consequentes crises: dos fundamentos da EA, do paradigma filosófico metafísico, da racionalidade ocidental, e do sujeito, do esgotamento do sistema capitalista (...) (PEREIRA, 2016, p. 45).

Neste horizonte, acreditamos que a Ecologia Política nos auxilia na compreensão e identificação acerca das injustiças ambientais, bem como na problematização do contexto a partir da lógica dominante presente nos projetos e nas concepções educativas, tais como nas propostas de Educação Ambiental. Por outro lado, esta conduta critica, aliada a um horizonte compreensivo, de intuição hermenêutica, como a Ecologia Cosmocena nos apresenta, parece conduzir a uma transformada postura: buscando novas relações entre natureza e humanidade.

\section{Considerações}

A partir do estudo, é possível compreender que as práticas realizadas na comunidade de pesca artesanal da llha da Torotama, fazem parte de uma proposta que abarca os espaços rurais do município. Essa proposta, de "promover a Educação Ambiental" não demonstra ser um projeto articulado as comunidades de pesca, no qual a comunidade apresente seus desafios, necessidades e enfrentamentos, mas é posta enquanto sujeito passivo na 
elaboração de ações que visem uma proposta de Educação Ambiental. Podemos identificar esse aspecto ao perceber certa resistência da comunidade quanto à inserção da EMATER, que responde tal manifestação culpabilizando os pescadores artesanais pela crise do pescado, sem, contudo, discutir a pesca predatória industrial e outros fatores cruciais presentes nas causas dos problemas enfrentados pelos pescadores locais.

Essa visão do Estado em relação as comunidades tradicionais e a Educação Ambiental, identificada por meio dos relatórios estudados, com o auxílio da ecologia política, demonstram o contexto no qual os valores do mercado globalizado invadem países como o Brasil. Nessa lógica, não há uma relação bem articulada com as comunidades específica, pois as responsabilidades com as áreas como educação e meio ambientes são relegadas às "parcerias" junto a esfera privada, como é o caso das ações aplicadas pela EMATER na Torotama.

Com efeito, encontramos por meio da análise, num horizonte crítico com o respaldo da Ecologia Política, uma Educação Ambiental forjada a partir de fundamentos de cunho cientificista que tem seus desdobramentos a partir da lógica moderna de se conceber ciência, tendo o logocentrismo a serviço de uma racionalidade instrumental, que ganha sua expressão máxima a partir da tecnocracia tão presente na lógica neoliberal.

Assim, o estudo realizado provoca o campo da ciência e da educação para uma produção de conhecimento mais participativa e que conceba os diversos saberes historicamente negligenciados de maneira em que seja possível um enfrentamento a essa concepção de Educação Ambiental muitas vezes ainda presente num tempo mais recente por meio dos projetos que 0 Estado assume. Acreditamos que a Educação Ambiental assume outras possibilidades se estiverem calcadas em uma proposta dialógica, participativa e crítica. Ressaltamos que por ser um campo múltiplo, a Educação Ambiental precisa estar em constante avaliação, de maneira em que possamos identificar quais as intencionalidades e quais os tensionamentos presentes em cada planejamento que se assuma enquanto tal.

Por fim, sugerimos a Ecologia Cosmocena como uma possibilidade de reconhecimento destes saberes outros, que desde sempre estão postos e reinventando-se; bem como instigando a emergência de novos olhares frente aos projetos de Educação Ambiental tão necessários a contrapor a lógica das opressões.

\section{Referências}

ACSELRAD, $H$. Las políticas ambientales ante las coacciones de la globalización. In: ALIMONDA, H. Los tormentos de la materia. Aportes para una ecología política latinoamericana. CLACSO, Consejo Latinoamericano de Ciencias Sociales, Buenos Aires. Marzo 2006. Disponível: $<$ http://bibliotecavirtual.clacso.org.ar/ar/libros/grupos/hali/C8HAcselrad.pdf> Acesso: junho de 2014.

Revbea, São Paulo, V. 11, № 5: 89-100, 2017. 
CARDOSO, E.S. Geografia e pesca: aportes para um modelo de gestão. Revista do Departamento de Geografia. São Paulo: USP, 2001.

DIEGUES, A.C. Povos e mares: leituras em sócio-antropologia marítima. São Paulo: NUPAUB-USP, 1995.

DIEGUES, A.C. As ilhas e arquipélagos tropicais brasileiros: práticas sociais e simbólicas. In. DIEGUES A.C. Ilhas e sociedades insulares. Coletânea de textos apresentados no Seminário: Sociedades Insulares (30 a 31 de julho de 1996). NUPAUB-USP, 1997.

DIEGUES, A.C. Povos e mares: leituras em sócio-antropologia marítima. São Paulo: NUPAUB-USP, 1995.

EMATER, Relatório. Rio Grande de 1991 a 1993, 1994. Acervo EMATER Rio Grande/RS.

EMATER, Relatório. Rio Grande ano de 1994, 1995. Acervo EMATER Rio Grande/RS.

KALIKOSKI, D.C.; VASCONCELLOS, M. Estudo de caso das condições técnicas, socioeconômicas e ambientais da pesca em escala reduzida no estuário da Lagoa dos Patos, Brasil. Uma metodologia para avaliação. FAO Fisheries and Aquaculture. Circular n.ำ 1075.ROME, 2012.

LAM, M. Consideration of customary marine tenure system in the establishment of marine protected areas in the South Pacific. Ocean \& Coastal Management. Delaware, USA, 1998.

LE GOFF, J. A história nova. São Paulo: Martins Fontes, 1995.

LEFF, E. La Ecología Política en América Latina: un campo em construcción. Estado Soc. vol. 18 ํo 1-2. Brasília. Janeiro/fevereiro, 2003.Disponível em: $<$ http://www.scielo.br/scielo.php?script=sci arttext\&pid=S010269922003000100 $\underline{003}>$ Acesso em 02.06.2014 às 14h38min.

LIPIETZ, A. A Ecologia Política, solução para a crise da instância política? Ecologia política. Naturaleza, sociedad y utopía En: Buenos Aires Lugar. in: CLACSO, Consejo Latinoamericano de Ciencias Sociales Editorial/Editor 2002 Fecha Colección Desarrollo Sustentable; Crisis; Poder Politico; Politica; Ecologia; Ecologia Politica; Temas Capítulo de Libro Tipo de documento. Disponível em: <http://bibliotecavirtual.clacso.org.ar/clacso/gt/20100930021553/2lipietz.pdf > Acesso em 12.05.2014 às 11h09min.

MARTINS, C.A.A. No trabalho dos pescadores artesanais a Lagoa dos Patos vive e dá a vida. Revista Eletrónica de Geografía y Ciencias Sociales. Universidad de Barcelona. B. 21.741-98, Vol. VI, num. 119 (47), 1 de agosto de 2002. 
NIEDERLE, P.A.; GRISA, C. Transformações sócio-produtivas na pesca artesanal no Estuário da Lagoa dos Patos. Revista Eletrônica do Mestrado de Educação Ambiental. V16, janeiro-julho de 2006, Universidade Federal de Rio Grande, 2006.

OPUSZKA, P.R. Cooperativismo Popular: Os limites da organização coletiva do trabalho da pesca artesanal do extremo sul do Brasil. Tese de dissertação, Curitiba, 2010.

PEREIRA, V.A. Ecologia Cosmocena. A redefinição do espaço humano no cosmos. Juíz de Fora, MG: GARCIA Edizioni, 2016.

SVAMPA, M. Consenso de los commodities, giro ecoterritorial y pensamiento crítico en América Latina. Disponível em: $<$ http://maristellasvampa.net/archivos/ensayo59.pdf> Acesso em 30.09. 2015 às $12 \mathrm{~h} 35 \mathrm{~min}$. 